\title{
Victimología: urgente necesidad de promulgar una Ley General de Victimas
}

\section{Victimology: Urgent need to enact a General Law for Victims}

Ricardo Alfredo Díaz Bazán* http://dx.doi.org/10.21503/lex.v11i12.27

* Abogado por la Universidad Nacional Mayor de San Marcos, Magíster en Administración, Magíster en Derecho Civil, Doctor en Derecho, docente universitario de pregrado y postgrado en diferentes universidades del Perú, conferencista nacional e internacional, Decano de la Facultad de Derecho y Ciencia Política de la Universidad Alas Peruanas. 


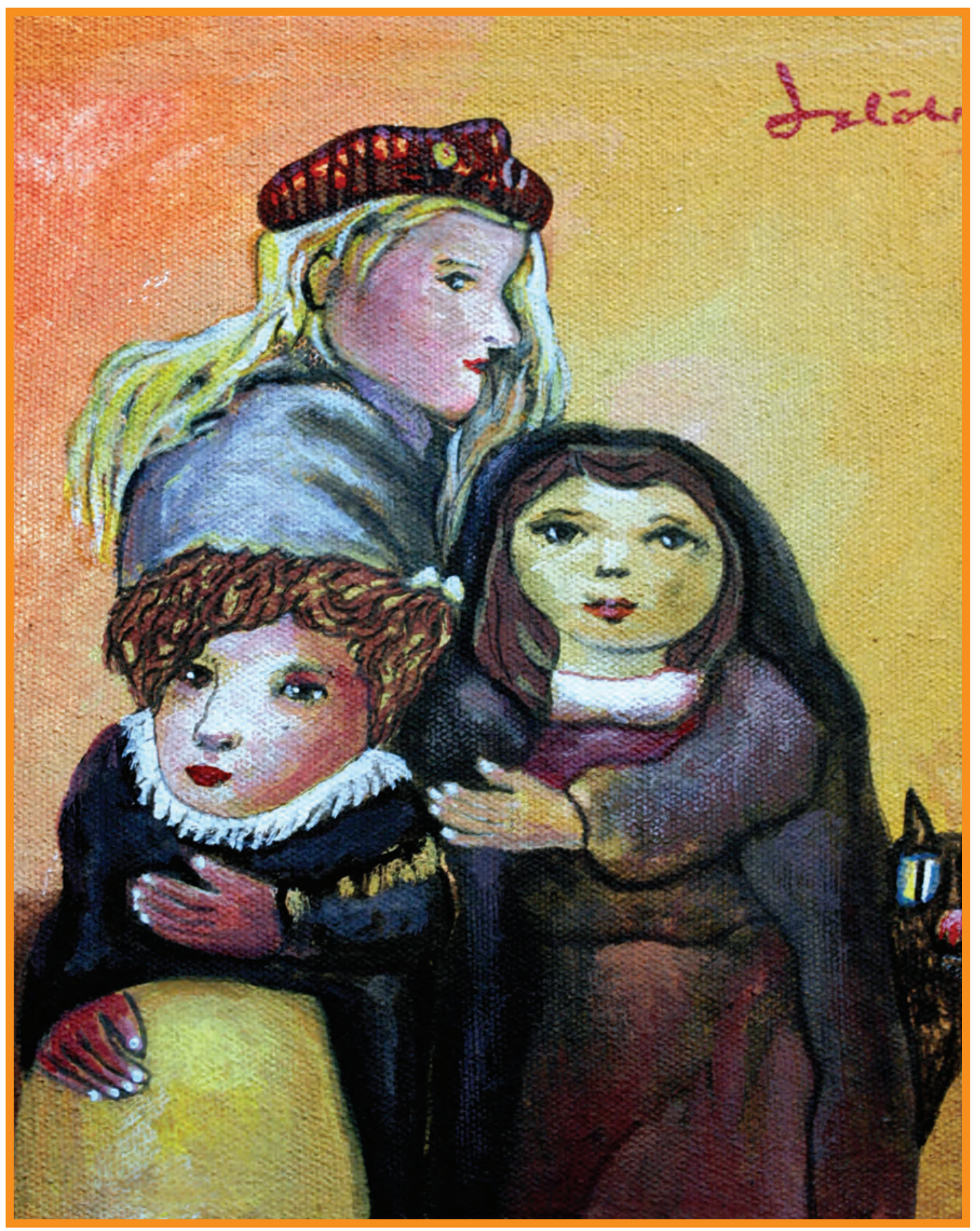

Niñas actuando. 


\section{RESUMEN}

El presente artículo tiene como objetivo justificar la urgente necesidad de promulgar una Ley General de Víctimas, a fin de que se dé una eficaz protección a las víctimas del delito, teniendo en cuenta que en nuestro ordenamiento penal el garantismo se ha centrado en los derechos de los delincuentes, quedando de lado los derechos de las víctimas, que con justicia buscan un resarcimiento pronto y equitativo del daño infligido. Además, se considera que la afección de los derechos de la víctima de un delito proviene no solo directamente del hecho delictivo sino de su misma intervención en el sistema penal que produce, muchas veces, una victimización múltiple. En ese sentido, es de vital importancia la Victimología, rama de la Criminología que tiene por objeto el estudio de la víctima de una infracción penal.

Palabras clave: victimología, victimización, Ley General de Victimas.

\section{ABSTRACT}

The present article aims to justify the urgent need to enact a Victim Act, so that effective protection is given to the victims of crime, considering that in our criminal law, the guarantor has focused on the rights of criminals, leaving aside the rights of victims who seek with justice a soon and equitable compensation of inflicted harm. Besides, it is considered that the condition of the rights of the victim of a crime comes not only directly in the crime but of their own involvement in the criminal justice system that produces multiple victimization many times. In that sense, the Victimology is very important, is a branch of the Criminology that aims to study of the victim of a criminal offense.

Key words: victimology, victimization, Ley General de Victimas (General Law for Victims). 



\section{INTRODUCCIÓN}

Nuestro ordenamiento legal desprotege los derechos y garantías de la víctima. Si bien es cierto el Nuevo Código Procesal Penal ha traído importantes innovaciones legislativas que permiten a la víctima constituirse en actor civil y participar activamente dentro del proceso penal, ello no significa que la víctima cuente con garantías mínimas para su reparación integral, es decir, devolver a la víctima a la situación anterior a la comisión del delito.

La víctima del delito ha padecido un secular y deliberado abandono. Si bien disfrutó del máximo protagonismo en la justicia primitiva considerada su edad de oro, ${ }^{1}$ después fue drásticamente neutralizada por el sistema legal moderno. Tal vez porque nadie quiere identificarse con el "perdedor", la víctima soporta los efectos del crimen (físicos, psíquicos, económicos, sociales, etc.), pero también la insensibilidad del sistema legal, el rechazo, la falta de solidaridad de la comunidad y la indiferencia de los poderes públicos.

La víctima, por su parte, no solo sufre la victimización primaria que ocurre en el momento del delito, sino sobre todo la secundaria, que ocurre cuando entra en contacto con el sistema. Sin embargo, no puede haber exceso y debe evitarse el retorno de la justicia privada o que sirva de pretexto para la reducción de derechos y garantías fundamentales del acusado o aun que se transforme la justicia en un market system (“justicia mercantilista”). ${ }^{2}$

\section{ANTECEDENTES Y CONCEPTO DE VÍCTIMA}

En la historia del Derecho Penal es posible distinguir dos grandes fases en cuanto a la relevancia del papel de la víctima. Inicialmente, en el Derecho Romano primitivo, en el derecho de los pueblos germánicos y en alguna medida, en el Derecho Medieval, fue posible asistir a lo que se conoce como "edad de oro" de la víctima.

Citado por Antonio García-Pablos de Molina. Criminología. Primera edición. Instituto Peruano de Criminología y Ciencias Penales. Centro de Educación Continua, 2008, p. 70.

2 Luiz Flavio Gomes. "La Victimología y el modelo consensual de justicia criminal". En: Revista Peruana de Doctrina y Jurisprudencia Penal. Grijley, 2000. 
En tales épocas, la reacción frente al ilícito quedaba prácticamente en manos del sujeto pasivo del mismo o de sus allegados, quienes devolvían la ofensa sobre la esfera jurídica del sujeto activo, es decir, sobre sus bienes o los de sus familiares, de modo ni siquiera coincidente con una genérica proporcionalidad en los términos del ius talionis. ${ }^{3}$ Era el Derecho Penal de la venganza privada. ${ }^{4}$

Progresivamente, sin embargo, se produjo la consolidación del Derecho Penal como Derecho Público, y, con el advenimiento del Estado moderno, el ejercicio del ius puniendi pasó a constituir monopolio de las instituciones del Estado. ${ }^{5}$ Asimismo, tuvo lugar el crecimiento y diferenciación del Derecho Civil y el Derecho Penal, como disciplinas que se ocupan, respectivamente, de la relación entre el delincuente y la víctima en lo relativo a la correspondiente pretensión indemnizatoria y de la relación entre delincuente y Estado. ${ }^{6}$

\section{VÍCTIMA Y VICTIMOLOGÍA}

Jorge Sosa Chacín, profesor venezolano citado por Solís Espinoza (1968), define a la Victimología como una rama de la criminología que tiene por objeto el estudio de la víctima resultante de la infracción penal.

En cuanto al concepto de Victimología, podemos anotar que puede ser abordado desde varias perspectivas. Desde un punto de vista etimológico procede de los vocablos "víctima" de origen latino y "logos" de raigambre griega. Lo que significaría ciencia o estudio de la víctima. ${ }^{8}$

La Victimología ha impulsado durante los últimos lustros un proceso de revisión científica del rol de la víctima en el fenómeno criminal, una redefinición del mismo a la luz de los conocimientos empíricos actuales y de la experiencia acumulada. Protagonismo, neutralización y redescubrimiento son, pues, tres lemas que podrían reflejar el estatus de la víctima del delito a lo largo de la historia.?

3 Citado por Jesús María Silva Sánchez. "La Víctimología desde la política criminal y el Derecho Penal. Introducción a la 'Victimodogmática”'. En: Revista Peruana de Ciencias Penales. Año II, No 4, julio-diciembre 1994, p. 596.

4 Antonio García-Pablos de Molina. "La resolución de la víctima. Víctima, sistema letal y política criminal". En: Criminología y Derecho Penal al servicio de la persona. Libro homenaje al Prof. Antonio Beristain. San Sebastián, 1989, pp. 193-197.

5 Jesús María Silva Sánchez. "La Víctimología desde la política criminal y el Derecho Penal. Introducción a la "Victimodogmática”". En: Revista Peruana de Ciencias Penales. Año II, No 4, julio-diciembre 1994, p. 596.

6 Roxin, Claus: "La reparación en el sistema jurídico-penal de sanciones", traducción de Manzanares, Jornada sobre la Reforma del Derecho Penal en Alemania, C.G.P., Madrid 1991, p. 1.

7 Jorge Sosa Chacín. "La Victimología, pretendida ciencia autónoma". En: Revista de la Facultad de Derecho. Caracas, 1968, $\mathrm{N}^{\circ} 40$.

8 Alejandro Solís Espinoza. “Criminología y Victimología”. En: Debate Penal. Revista cuatrimestral, año I, No 3, setiembrediciembre de 1987 , p. 511.

9 Citado por Antonio García-Pablos de Molina. Criminología. Primera edición. Instituto Peruano de Criminología y Ciencias Penales. Centro de Educación Continua, 2008, p. 70. 
En tanto, Sánchez Velarde ${ }^{10}$ define a la víctima como aquella persona, grupo, entidad o comunidad afectada por la comisión del delito, aunque no sea, específicamente, la tenida en cuenta por el sujeto activo del delito. Comúnmente es la persona que sufre la acción delictiva $\mathrm{y}$ aparece en el proceso penal como agraviada.

Peña Cabrera ${ }^{11}$ señala que la víctima es aquella persona que ve afectados sus bienes jurídicos o disminuidos su capacidad de disposición de aquellos, como consecuencia de la conducta infractora de una norma jurídico-penal, pudiendo ser el agente culpable e inculpable.

Todos coincidimos en que la víctima es aquella persona natural o jurídica que se ha visto afectada por la comisión de un hecho punible.

\section{LA VICTIMIZACIÓN Y SUS CONSECUENCIAS}

La víctima de un delito padece una serie de afecciones a sus derechos que provienen directamente del hecho delictivo y otros que se derivan de su intervención en el sistema penal. Y aun puede padecer otros más que se derivan de los anteriores. Todos estos daños son sumamente graves y es preciso que las personas que fungen como operadores de justicia se encuentren plenamente conscientes de estos, a efectos de generar una intervención que proteja íntegramente sus derechos. ${ }^{12}$ Por ello es importante y vital que el estado ponga sus ojos en la víctima, para que no se permita el doble desamparo a la víctima.

Victimización primaria. Jorge Mesas refiere que se denomina "victimización primaria al resultado de la acción delictiva que, al recaer sobre una o más personas, las convierte en víctimas; es por tanto aquel efecto del delito que se produce cuando la acción delictiva afecta a alguna persona en concreto, a la cual causa una serie más o menos extensa de perjuicios, padecimientos y menoscabo o privación de derechos". ${ }^{13}$ Es decir, la victimización primaria es el resultado de la comisión del hecho punible en perjuicio del agraviado.

Victimización secundaria. La Victimología se encargó de poner en evidencia la muy desfavorable posición en que se encontraba la víctima en el proceso penal y los escasos derechos que podía ejercer dentro de él. Las denuncias formuladas por la Victimología eran fácilmente contrastables en la realidad, donde era observable que los derechos fundamentales de las víctimas se ven afectados con ocasión del proceso y no solo con la acción del imputado. ${ }^{14}$

10 P. Sánchez Velarde. El nuevo proceso penal. Lima: IDEMSA, 2009, p. 81.

11 A. Peña Cabrera Freyre. Exégesis. Nuevo Código Procesal Penal. 2da. edición. Bilbao: Editorial Praxis, 1999, p. 421.

12 Elky Villegas Paiva. El agraviado y la reparación civil en el nuevo Código Procesal Penal. Primera edición. Editorial Gaceta Jurídica, 2013, p. 62.

13 Luis Francisco Jorge Mesas. "La eficacia del sistema penal”. En: Cuadernos del Poder Judicial. Dedicado a Criminología. Consejo General del Poder Judicial. Madrid, 1994, p. 63.

14 Elky Villegas Paiva. El agraviado y la reparación civil en el nuevo Código Procesal Penal. Primera edición. Editorial Gaceta Jurídica, 2013, p. 63. 
Cuando la víctima acude ante los órganos de Justicia, Policía, Fiscalía, Poder Judicial, a efectos de presentar una denuncia, pese a hacerlo bajo los efectos del daño sufrido y, sin embargo, con una valiosa actitud de colaboración para el esclarecimiento del delito y coadyuvar con las investigaciones, generalmente no recibe una atención adecuada, ni una asistencia inmediata, no es informada debidamente sobre el proceso y pasos a seguir, no recibe un trato respetuoso y mucho menos equitativo, no cuenta con información efectiva sobre sus derechos, en suma, es maltratada por el sistema legal. ${ }^{15}$ En todo caso, es tratada como un testigo del hecho, puesto que para el sistema la prioridad es la sanción penal.

En el Perú es generalizado el sentimiento de desprotección y de desconfianza que sienten los ciudadanos ante las instituciones encargadas de dar protección a la población tras la comisión de un hecho delictivo. Así lo reflejan muchas de las encuestas realizadas a la población civil peruana. Sirva de ejemplo la encuesta de victimización que evidencian un amplio porcentaje de entrevistados que consideran que es probable que en los próximos doce meses sean víctimas de algún delito, lo que significa el cuestionamiento de la eficacia del trabajo de las fuerzas del orden público y la credibilidad de las mismas, como factores determinantes de la percepción de seguridad. ${ }^{16}$

Por ello, esta victimización secundaria es considerada como la más negativa, ya que es producida por el propio sistema, que revictimatiza a quien se dirige a él precisamente para buscar protección y apoyo. Esta desprotección por el sistema legal, contradice el artículo $1^{\circ}$ de nuestra Constitución Política del Perú, que establece que la persona humana es el fin supremo del Estado.

La victimización terciaria. Procede de la conducta posterior de la misma víctima, y a veces emerge como el resultado de las vivencias y de los procesos de adscripción y etiquetamiento, como consecuencia o valor añadido de las victimizaciones primarias y secundarias precedentes. Por ejemplo, cuando la víctima, consciente de su victimización primaria y secundaria admite un resultado, en cierto sentido paradójicamente exitoso (fama en los medios de comunicación, aplausos de grupos extremistas, etc.). Luego, deduce que le conviene aceptar esa nueva imagen de sí mismo (a) y decide, desde y a través de ese rol, vengarse de las injusticias sufridas y de su victimarios (legales a veces). Para vengarse, se autodefine y actúa como delincuente, como drogadicto, etc. ${ }^{17}$

15 Elky Villegas Paiva. El agraviado y la reparación civil en el nuevo Código Procesal Penal. Primera edición. Editorial Gaceta Jurídica, 2013, p. 64

16 Elky Villegas Paiva. El agraviado y la reparación civil en el nuevo Código Procesal Penal. Primera edición. Editorial Gaceta Jurídica, 2013, p. 69.

17 Elky Villegas Paiva. El agraviado y la reparación civil en el nuevo Código Procesal Penal. Primera edición. Editorial Gaceta Jurídica, 2013, p. 70. 


\section{VICTIMOLOGÍA: COMPENSACIÓN Y ASISTENCIA ${ }^{18}$}

Hay que anotar, así como lo han dicho otros tantos estudiosos, que la víctima debe ser también asistida en los problemas o necesidades que son secuelas del hecho de haber sido victimizado, En otros términos, diremos que los derechos de las víctimas quizá deberían ser más prevalentes que los derechos del recluso o interno, que han cobrado mayor auge.

Aunque parezca paradójico, nuestro Código de Ejecución Penal vigente, Decreto Legislativo $\mathrm{N}^{\circ} 654$ publicado el 02 de agosto de 1991, en cumplimiento de normas internacionales, ha previsto en su Título III, "Tratamiento penitenciario para el interno", protegerlo con trabajo, educación, salud, asistencia social, asistencia legal gratuita, asistencia psicológica y asistencia religiosa. El tratamiento penitenciario tiene como objetivo la reeducación, rehabilitación y reincorporación del interno a la sociedad; consecuentemente, tiene más derechos que la víctima.

Refiere Solís Espinoza que hay que tener en cuenta que las necesidades de las víctimas son complejas y van desde las económicas, asistencia de salud física y problemas de carácter social y laboral, que son efectos del acto criminal. Asimismo, existen víctimas indirectas, como los hijos huérfanos, debido al homicidio de su ascendiente, o padres desamparados que dependían de la víctima, entre otros casos.

El VII Congreso de las Naciones unidas reseñó que la presentación de servicios y asistencia a las víctimas, en muchos países, se encaraba como parte de todo sistema de bienestar o seguro social. En el Derecho Comparado, casi todos los países han suscrito normas de una eficaz protección, reconociendo derechos a la víctima.

A manera de ejemplo citaremos la reciente Ley General de Víctimas de México, publicada el 09 de enero del 2013, que ha otorgado importantes derechos y protección a la víctima, entre los que tenemos:

I. Reconocer y garantizar los derechos de la víctima del delito y de violaciones a derechos humanos, en especial el derecho a la asistencia, protección, atención, verdad, justicia en ella, en la Constitución, en los Tratados internacionales de derechos humanos de los que el Estado de México es parte y demás instrumentos de derechos humanos.

II. Establecer y coordinar las acciones y medidas necesarias para promover, respetar, proteger, garantizar y permitir el ejercicio efectivo de los derechos de las víctimas; así como implementar los mecanismos para que todas las autoridades en el ámbito de sus respectivas competencias cumplan con sus obligaciones de prevenir, investigar, sancionar, y lograr la reparación integral.

18 Alejandro Solís Espinoza. Criminología y Victimología. En debate penal, cuatrimestral, año I, Nº 3, setiembre - diciembre, 1987 , p.511. 
III. Garantizar un efectivo ejercicio del derecho de las víctimas a la justicia en estricto cumplimiento de las reglas del debido proceso.

IV. Establecer deberes y obligaciones específicos a cargo de las autoridades y de todo aquel que intervenga en los procedimientos relacionados con la víctima.

V. Establecer las sanciones respecto al incumplimiento por acción o por omisión de cualquiera de sus disposiciones.

Otra protección importantísima que nos trae la novísima Ley General de Víctimas de México es el contemplado en su artículo $64^{\circ}$, es decir, otorgar la compensación en caso de comisión de los delitos considerados como graves en aquellos casos en que la víctima haya sufrido daño o menoscabo a su libertad, o si la víctima directa hubiera fallecido o sufrido un deterioro incapacitante en su integridad física y/o mental como consecuencia del delito, incluyendo el error judicial, de conformidad con lo que establece la Ley y su Reglamento. Estos perjuicios, sufrimientos y pérdidas incluirán como mínimo:

I. La reparación del daño sufrido.

II. La reparación del daño moral sufrido por la víctima o las personas con derecho a la reparación integral.

III. El resarcimiento de los perjuicios ocasionados o lucro cesante.

IV. La pérdida de oportunidades, en particular las de educación y prestaciones sociales.

V. Los daños patrimoniales generados como consecuencia de delitos o violaciones a derechos humanos.

VI. El pago de los gastos y costas judiciales del Asesor Jurídico cuando este sea privado.

VII. El pago de tratamientos médicos o terapéuticos que, como consecuencia del delito o de la violación de derechos humanos, sean necesarios para la recuperación de la salud psíquica y física de la víctima.

VIII. Los gastos de transporte, alojamiento, comunicación o alimentación que le ocasione trasladarse al lugar del juicio o para asistir a su tratamiento, si la víctima reside en municipio o delegación distintos al del enjuiciamiento o donde recibe la atención.

En nuestro país se ha intentado otorgar una defensa técnica a la víctima, que implica un derecho a ser asesorada por un abogado, el que debería proveerle el Estado. A tal efecto, se ha implementado por el Ministerio Público, dentro de su Unidad de Asistencia a Víctimas 
y Testigos (UDAVIT), un equipo de profesionales del Derecho que deberían asesorar a las víctimas en todo lo que necesiten; sin embargo, es de reconocer que su efectividad actualmente es muy relativa. ${ }^{19}$

Corresponderá al abogado asignado a la víctima del delito, perteneciente a la UDAVIT, asesorarla, informarle sobre sus derechos, explicarle los mecanismos para que se hagan efectivos, o gestionarlos cuando corresponda, mantenerla permanentemente informada de las actuaciones y pormenores del procedimiento penal. ${ }^{20}$

Asimismo, muy a pesar de que el Estado ha expedido normas como la Resolución Nro. 1558-2008-MP-FN del 12 de noviembre del 2008, denominada "Reglamento del Programa de Asistencia a Víctimas y Testigos", y el D. S. N $003-2010$ - JUS, publicado en el Diario Oficial el Peruano el 13 de Febrero del 2010, por el que "Aprueban reglamento del Programa Integral de Protección a testigos, peritos, agraviados o colaboradores que intervengan el Proceso penal", estas no han cubierto las necesidades básicas de la víctima. A la fecha no se ha implementado con eficiencia y responsabilidad las verdaderas garantías mínimas a la víctima.

\section{MARCO LEGAL DE PROTECCIÓN A LA VÍCTIMA ${ }^{21}$}

\section{A nivel internacional}

a) Convención de la Naciones Unidas contra la Delincuencia Organizada Transnacional (noviembre 2000), también conocida como la "Convención de Palermo".

La Organización de las Naciones Unidas (ONU) tomó la iniciativa para, diseñar en conjunto, una herramienta legal que guíe la lucha contra la delincuencia organizada; así, luego del análisis pertinente, arduas deliberaciones y debates previos que se prolongaron por casi tres años, los especialistas tradujeron las inquietudes de los pueblos sobre esta materia volcándolas en este documento.

El artículo 25 de la Convención de las Naciones Unidas contra la Delincuencia Organizada Transnacional prescribe "asistencia y protección a las víctimas", consignando que "(...) Cada Estado parte adoptará medidas apropiadas dentro de sus posibilidades para prestar asistencia y protección a las víctimas de los delitos comprendidos en la presente Convención, en particular en casos de amenaza, represalias o intimidación".

19 Gaceta Penal y Procesal Penal. "Consultas. ¿Cómo se configura el derecho de la defensa del agraviado o víctima del delito en el proceso penal?”. Tomo 46, abril 2013.

20 Ibidem.

21 Omar Levi Rosillo Sánchez. "La víctima y el testigo en el Código Procesal Penal de 2004". En: Revista de Actualidad Jurídica. Nro. 197, 2010, p. 133. 
Cabe mencionar que la citada Convención consideró entre sus logros la tipificación como delitos internacionales de la asociación para delinquir, del lavado de dinero y la obstrucción a la justicia, que hasta entonces solo habían sido objeto de esfuerzos legislativos nacionales; pero además, puso especial énfasis en mecanismos de ayuda a las víctimas, protección de testigos y medidas para defender el comercio internacional de la infiltración de grupos criminales.

b) Otro instrumento importante es la Convención de las Naciones Unidas contra la Corrupción, que en sus artículos 32 y 33 regula expresamente la protección de testigos, peritos y víctimas, especificando las medidas de protección y la posibilidad de los Estados parte de incorporar en su marco normativo medidas apropiadas para proporcionar protección a las personas que denuncien ante las autoridades competentes, de buena fe, y con motivos razonables, cualesquiera hechos relacionados con delitos tipificados con arreglo a la presente Convención, poniendo énfasis en el respeto a los derechos y a las garantías procesales.

Por eso se entiende que muchos países de Latinoamérica hayan iniciado un proceso acelerado para incluir en sus legislaciones normas de protección a víctimas y testigos, con la finalidad de proteger a sus ciudadanos y sobre todo enfatizar en la lucha contra el crimen, coincidiendo varias de ellas con la ejecución de la reforma procesal penal, cuya característica primordial incide en el cambio del vetusto sistema inquisitivo (escrito) por el ágil y eficaz sistema acusatorio (oralidad), tal y conforme aconteció en Colombia, Chile, Venezuela, Argentina, Ecuador, El Salvador y, progresivamente, en el Perú.

Por otro lado, la mayoría de los países que conforman nuestra región no han sido ajenos a tratar, discutir, deliberar, proponer, diseñar, aprobar y perfeccionar los mecanismos y estrategias a favor de la protección de víctimas y testigos. Prueba de ello es que en los últimos años se han realizado reuniones de trabajo, seminarios, asambleas, así como encuentros académicos entre fiscales de Iberoamérica y especialistas (Colombia, Chile, Ecuador, Venezuela, Brasil, Argentina, Uruguay, Bolivia, Paraguay, Perú, Italia, México, Honduras, Panamá, Nicaragua, El Salvador, USA, Canadá, España, Portugal, Letonia), que contando a su vez con la asistencia de funcionarios y expertos de la OEA, Unión Europea, Corte Penal Internacional, la Asociación Iberoamericana del Ministerio Público - AIAMP, y el continuo apoyo de AECI, posibilitan una adecuada capacitación y una alta preparación para afrontar el reto de la lucha contra el crimen organizado, compromiso en el cual se encuentra involucrado el Ministerio Público de nuestro país.

Destaca, en tal sentido, la XVI Asamblea General Ordinaria de la Asociación Iberoamericana de Ministerios Públicos (AIAMP), que se llevó a cabo en República Dominicana, los días 9 y 10 de julio del 2008, y en la cual se aprobó un importante documento denominado "Guías de Santiago sobre Protección de Víctimas y Testigos". 


\section{A nivel nacional}

Rosillo Sánchez refiere ${ }^{22}$ que el artículo $1^{\circ}$ de la Constitución Política del Perú establece que "la persona humana es el fin supremo del Estado". En consecuencia, con este principio se debe interpretar que es posible establecer asistencia y protección a favor de las víctimas, y más aun como integrantes de la sociedad son involucrados circunstancialmente, adquiriendo tal condición como consecuencia de la perpetración de un delito. Ahora bien, nuestra legislación interna no ha recogido de manera adecuada la regulación sobre esta materia, pero sí ha suscrito los instrumentos internacionales antes citados, que sirven de marco para efectuar un desarrollo posterior.

En tal sentido, atendiendo a lo prescrito en el inciso c) del numeral 1 del artículo 95 y en el numeral 4) del artículo 170 del Código Procesal Penal del 2004, la Fiscalía de la Nación emitió la resolución Nro. 1558-2008 MP-FN del 12 de noviembre del 2008, aprobando una serie de normas reglamentarias, entre los cuales destaca el "Reglamento del Programa de Asistencia a Víctimas y Testigos", necesario para delimitar el procedimiento a ejecutar en aquellos casos en los que los ciudadanos peruanos o extranjeros que, teniendo la calidad de testigos o víctimas, necesitaran de asistencia.

Debe indicarse que su incorporación al programa es voluntaria y gratuita, y su aplicación se extiende a todo el territorio de la República y resulta de obligatorio cumplimiento para los fiscales y oficinas de apoyo correspondiente.

Es así como se puede referir que los primeros beneficios que se establecieron en este tema datan del año 2000, Ley $\mathrm{N}^{\circ} 27378$ (Ley que establece los beneficios por colaboración eficaz en el ámbito de la criminalidad organizada, reglamentada mediante Decreto Supremo Nro. 035-2001-JUS.

Con la dación del Código Procesal Penal de 2004 se incorporan medidas de protección de testigos, peritos, agraviados o colaboradores que interviniesen en el proceso penal, conforme se observa en los artículos 247 a 252, los que, además de considerar las medidas de protección (anteriormente contempladas en la Ley de colaboración eficaz), ampliaron sus alcances a fin de satisfacer los estándares internacionales, regulando medidas adicionales, como traslado de vehículos adecuados (blindados), custodia policial, habilitación de ambientes exclusivos, cambio de identidad, relocalización nacional y/o internacional.

22 Ibidem. 


\section{LAS VÍCTIMAS EN EL CÓDIGO DE PROCEDIMIENTOS PENALES DE 1940}

Con relación a la actuación del agraviado durante el proceso penal para los delitos comunes, el Código de Procedimientos Penales establece:

Parte Civil: El artículo $54^{\circ}$ señala quiénes pueden constituirse: el agraviado, sus descendientes o descendientes, su cónyuge, sus parientes colaterales y afines dentro del segundo grado; sus padres o hijos adoptivos o su tutor o curador pueden constituirse en parte civil. La persona que no ejerza por sí sus derechos será representada por sus personeros legales.

Facultades de la parte civil: Los artículos $57^{\circ}$ y $58^{\circ}$ regulan la actuación de la parte civil acerca de su personería, los recursos a interponer y la facultad para ofrecer pruebas

Embargo: También se norma lo relativo a la medida de embargo, en el artículo 94º, a efectos de asegurar la posible reparación civil que resulte del proceso

Sentencia condenatoria: El artículo $285^{\circ}$ establece que la sentencia condenatoria deberá contener, entre otros aspectos, el monto de la reparación civil.

\section{LAS VÍCTIMAS EN EL CÓDIGO PROCESAL PENAL DEL 2004}

Neyra Flores ${ }^{23}$ refiere que nuestro Código Procesal Penal ha recogido este movimiento por el adecuado tratamiento legislativo de la víctima; por ello, su título IV titulado "La víctima" (dentro de la sección IV "El Ministerio Público y los demás Sujetos procesales") contiene tres capítulos: el agraviado, el actor civil y el querellante particular, todas ellos relacionados con las personas que han sufrido algún tipo de menoscabo a raíz de un delito pero que se diferencian la una de la otra en el tratamiento legislativo que el Código prodiga; por ello, antes de seguir haciendo esta referencia, es bueno que tengamos en claro algunos conceptos como ofendido, perjudicado y agraviado que usa el NCPP.

- Ofendido es aquella persona que de manera inmediata sufre los efectos de la conducta criminal, es decir, aquella persona contra la que el sujeto activo dirige su conducta delictiva.

o Perjudicado es aquel a quien el delito ha producido cualquier clase de perjuicio, es decir, el sujeto pasivo del daño indemnizable o el titular de intereses directa e indirectamente lesionado por el delito, que deduce expresamente en el proceso penal una pretensión patrimonial causada por la comisión del delito.

o Agraviado es el ofendido o el perjudicado que por su sola calidad de ser tal goza de derechos,

${ }^{23}$ José Antonio Neyra Flores. Manual del Nuevo Proceso Penal y de litigación oral. IDEMSA, 2010, p. 255. 
sin necesidad de constituirse en parte civil; en ese sentido, es un concepto comprensivo de los arriba explicados. Con ello, busca proteger su rol como sujeto procesal.

o Actor civil es una categoría procesal de larga data. Para ser actor civil, el ofendido o perjudicado deben constituirse expresamente como tal y deducir la correspondiente pretensión patrimonial en el proceso penal.

En Colombia, señala Guerrero Peralta, ${ }^{24}$ en el marco de la implementación de un sistema acusatorio, una de las innovaciones que más interesa es la función impuesta a la Fiscalía General de la Nación con relación a las víctimas, pues de acuerdo con una primera aproximación a este acto reformatorio a la Carta Política, el constituyente ha reformulado toda la concepción existente en cuanto a la participación de las víctimas en el proceso penal que se configura a partir de tres fundamentos. El primero establece que una de las causales para la adopción de medidas restrictivas de la libertad es la relativa a la protección de la comunidad y, en el contexto de aquella, la norma establece que debe haber una especial consideración a la protección de las víctimas. El segundo fundamento constitucional le impone a la Fiscalía General de la Nación la tarea de solicitar ante el Juez de conocimiento las medidas judiciales necesarias para la asistencia a las víctimas y, al mismo tiempo, la norma faculta al fiscal para requerir del Juez el restablecimiento del derecho y la reparación integral de los afectados con el delito. El último fundamento no es novedoso y hace relación a la función tradicional de velar por la protección de la víctima al lado de los Jurados y los testigos. No obstante, en la misma disposición se remite a la ley para que esta fije los términos en que podrán intervenir las víctimas en el proceso penal y la adopción de mecanismos de justicia restaurativa a que haya lugar.

\section{EL AGRAVIADO EN EL NUEVO CÓDIGO PROCESAL PENAL}

El Artículo $94^{\circ}$ del Código Procesal Penal peruano sostiene que es agraviado quien resulte directamente ofendido o perjudicado por las consecuencias del delito, con lo que se hace una distinción, sutil pero transcendente, entre el ofendido o víctima directa y perjudicado o víctima indirecta. El artículo 98 de la norma acotada ratifica esta lectura propuesta al establecer que perjudicado es quien, según la ley civil, está legitimado para reclamar la reparación y, en su caso, los daños y perjuicios producidos por el delito; con ello, se deja claro que el perjudicado es sujeto distinto a la víctima directa. ${ }^{25}$

La norma procesal en su artículo $94^{\circ}$ define al agraviado así:

1. Se considera agraviado a todo aquel que resulte directamente ofendido por el delito o perjudicado por las consecuencias del mismo. Tratándose de incapaces, de personas jurídicas o del Estado, su representación corresponde a quienes la ley designe.

${ }^{24}$ Citado por José Antonio Neyra Flores. Manual del Nuevo Proceso Penal y de litigación oral. IDEMSA, 2010, p. 254.

25 Luis Reyna Alfaro. El proceso penal aplicado. Grijley, 2011, p. 306. 
2. En los delitos cuyo resultado sea la muerte del agraviado, tendrán tal condición los establecidos en el orden sucesorio previsto en el artículo 816 del Código Civil.

3. También serán considerados agraviados los accionistas, socios, asociados o miembros respecto de los delitos que afecten a una persona jurídica, cometidos por quienes los dirigen, administran o controlan.

4. Las asociaciones en los delitos que afecten intereses colectivos o difusos, cuya titularidad lesione a un número indeterminado de personas, o en los delitos incluidos como crímenes internacionales en los tratados internacionales aprobados y ratificados por el Perú, podrán ejercer los derechos y facultades atribuidas por las personas directamente ofendidas por el delito, siempre que el objeto social de la misma se vincule directamente con esos intereses y haya sido reconocida e inscrita con anterioridad a la comisión del delito objeto del procedimiento.

\section{Derechos del agraviado}

La norma procesal en su artículo $95^{\circ}$ le reconoce los siguientes derechos:

o A ser informado de los resultados de la actuación en que se haya intervenido, así como del resultado del procedimiento, aun cuando no haya intervenido en él, siempre que lo solicite.

o A ser escuchado antes de cada decisión que implique la extinción o suspensión de la acción penal, siempre que lo solicite.

o A recibir un trato digno y respetuoso por parte de las autoridades competentes, y a la protección de su integridad, incluyendo la de su familia. En los procesos por delito contra la libertad sexual se preservará su identidad, bajo responsabilidad de quien conduzca la investigación o el proceso.

o A impugnar el sobreseimiento y la sentencia absolutoria.

o El agraviado será informado sobre sus derechos cuando interponga la denuncia, al declarar preventivamente o en su primera intervención en la causa.

o Si el agraviado fuera menor o incapaz, tendrá derecho a que durante las actuaciones en las que intervenga sea acompañado por persona de su confianza. 


\section{EL ACTOR CIVIL EN EL NUEVO CÓDIGO PROCESAL PENAL}

Vassallo Sambuceti ${ }^{26}$ señala que la parte o actor civil, en tanto pretende una reparación civil por el daño sufrido, debe probar la existencia del daño, lo que no necesariamente queda acreditado con la existencia del hecho punible. Siguiendo esa lógica, la parte civil debe probar que se encuentra legitimada para recibir la reparación por el daño sufrido; igualmente, debe acreditar que las personas de las que pretende el resarcimiento se encuentran obligadas en la relación jurídica civil sustantiva; así mismo, debiera probar la magnitud del daño, y como es lógico, la decisión judicial en torno a la reparación civil debe fundamentarse en un quantum eficazmente acreditado.

\section{Requisitos para constituirse en actor civil}

De acuerdo al artículo $100^{\circ}$ del NCPP, los requisitos para constituirse en actor civil son:

1. La solicitud de constituir en actor civil se presentará por escrito ante el Juez de la Investigación Preparatoria.

2. La solicitud debe contener, bajo sanción de inadmisibilidad:

a. Las generales de ley de las personas físicas o la denominación de la persona jurídica con las generales de ley de su representante legal;

b. La indicación del nombre del imputado y, en su caso, del tercero civilmente responsable, contra quien se va a proceder;

c. El relato circunstanciado del delito en su agravio y exposición de las razones que justifican su pretensión; y

d. La prueba documental que acredita su derecho, conforme al artículo $98^{\circ}$.

\section{EL QUERELLANTE PARTICULAR}

El proceso penal de un sistema acusatorio requiere, para su válido funcionamiento, que existan tres personas, cada una con una función especifica: defender, juzgar y acusar. Así, la acusación es un requisito esencial para que válidamente se constituya el proceso penal, pero esto no implica que el acusador tenga que ser siempre el Ministerio Publico a través del fiscal. ${ }^{27}$ Nuestro ordenamiento procesal ha establecido derechos del querellante particular en los delitos de ejercicio de la acción privada; es decir, el directamente ofendido por el delito

26 E. Vasallo Sambuceti. La acción civil en el proceso penal. Lima: Editorial San Marcos, 2000, p. 119.

27 José Antonio Neyra Flores. Manual del Nuevo Proceso Penal y de litigación oral. IDEMSA, 2010. 
podrá instar ante el órgano jurisdiccional, siempre conjuntamente, la sanción penal y pago de la reparación civil contra quien considere responsable del delito en su agravio.

Refiere Neyra Flores que en Chile y España la acción penal puede ser ejercida por la víctima. Sin embargo, este acusador privado, mal llamado querellante, en el NCPP peruano es la parte acusadora necesaria en los procesos penales por hechos delictivos perseguibles solo a instancia de parte, en los que queda excluida la intervención del Ministerio Público.

Para concluir con los derechos que amparan a la víctima, consideramos que nuestra norma procesal no ha sido efectiva en determinar el monto de la reparación civil, siendo muchas veces insuficiente, al no cubrir in extenso el daño causado.

\section{DETERMINACION DEL MONTO DE LA REPARACIÓN CIVIL}

Chinchay Castillo ${ }^{28}$ ha establecido el método OBC para determinar el monto de la reparación civil:

a) OBC (Ojo de Buen Cubero). Si hay alguna carencia clamorosa en el sistema penal, es alrededor de la absoluta impresión técnica para determinar el monto de la reparación civil. Esta se estima según el leal entender del operador; y allí reside una de las causas por las cuales casi nunca y a casi nadie satisface el monto de la reparación civil.

El magistrado penal no suele tomar en cuenta que las expresiones siguientes contienen una terrible exigencia técnica que implica cálculos que en no pocos casos son altamente complejos:

(1) "El pago de su valor" (del bien sustraído o siniestrado, si no es posible su devolución), del art. 93 del CP, inc. 1.

(2) "Daños y perjuicios", del artículo 93 del CP, inciso 2.

(3) "La reparación civil se rige, además, por las disposiciones pertinentes del Código Civil”, del artículo 101 del C.P.

b) Respecto de otros conceptos, hay que distinguir entre:

o Daño emergente

o Lucro cesante

o Daño moral

o Daño a la persona

o Incumplimiento

o Cumplimiento

28 Alcides Chinchay Castillo. “La víctima y su reparación civil”. En: Jurisprudencia Penal. N 108, setiembre 2007, p. 219. 
(1). Parcial

(2). Tardío

(3). Defectuoso

c) El tercer aspecto del daño moral no escapa a la falta de elemento o parámetro que permita determinar su equivalente en dinero, en razón de que no existe una correlación entre un sufrimiento y una cantidad de dinero que lo repare. Queda nuevamente sujeta a la "prudencia" del juzgador. De ahí que no pueda concederse una reparación exacta, lo que no significa que no deba concederse ninguna.

d) Los dos últimos conceptos nos llevan a la responsabilidad civil contractual, sobre la que otro yerro común es creer que la responsabilidad civil proveniente del delito solo puede ser extracontractual.

e) Lejos de todas estas implicancias en el tema de responsabilidad civil proveniente del delito, el magistrado penal aplica el método OBC, sin absolutamente ningún criterio técnico. Si le preguntáramos por qué en un determinado delito pidió o impuso digamos cinco mil nuevos soles y no tres mil, cuatro mil, cinco mil o diez mil, no sabría qué decir. En esto concurren dos factores:

(i) "Lo que no se usa se atrofia". Esto quiere decir que el magistrado penal que no esté habituado a pensar en derecho de daños se halla de algún modo incapacitado para aplicar un criterio apropiado en la solución de este problema, y está convencido de que su ponderación del daño depende de una suerte de corazonada y no de factores que tiene que sopesar.

(ii) El magistrado no tiene un conocimiento de la amplitud del daño, porque no suele establecerse un diálogo con la víctima en ese sentido. Y pese a este desconocimiento, el magistrado tiene que pronunciarse sobre una reparación civil acerca de la cual no sabe casi nada.

\section{LA REPARACION CIVIL EN FUNCIÓN DE LA CAPACIDAD ECONÓMICA DEL REO}

Chinchay Castillo ${ }^{29}$ señala lo siguiente:

a) La reparación civil no es una multa, no es una pena complementaria. En tanto ello, carece de sentido ponerla en relación con la capacidad económica del reo.

$29 \quad$ Ibidem. p. 223. 
b) La reparación civil es nada más ni nada menos aquella suma de dinero que permitirá que la persona dañada pueda restaurar las cosas al estado anterior a la vulneración o se vea adecuadamente compensada, si ello no es posible.

c) Por ejemplo, uno de los elementos (y no la totalidad) de la reparación en las lesiones sucedidas por un atropello es el costo de la recuperación médica del atropellado.

- ¿El costo de la operación y de las medicinas va a dejar de costar 50 nuevos soles y va a pasar a costar 500 nuevos soles solo porque el que causó el daño no tienen dónde caerse muerto? ¿Puede el perjudicado decirle a la tesorería de la clínica u hospital que deben cobrarle mucho menos que lo facturado porque el responsable del daño es indigente?

- Otra cosa completamente diferente es que no sea justo sacar consecuencias contrarias al condenado si él realmente no puede cubrir dicho monto por indigencia. Por ejemplo, que no se den beneficios penitenciarios porque no pagó el íntegro, o que no se le borren los antecedentes si no pagó el íntegro.

d) Pero eso es distinto de fijar el monto de la reparación en función de su capacidad económica. Y fijar un monto verdadero puede ayudar a la víctima para otros efectos:

- Deducciones tributarias.

- Ajustes de indemnización con su compañía de seguros.

- Eventualmente tener la expectativa de cobrar más adelante si la situación económica del condenado se mejora.

e) Mención aparte merece el pago de la reparación civil en forma solidaria con el tercero civilmente responsable, que como sabemos no se da en todos los casos. La obligatoriedad de esta persona puede posibilitar que se efectivice el pago respectivo, teniendo en cuenta que este sujeto procesal resulta ser aquella persona natural o jurídica que sin haber participado en la comisión del delito, y sin alcanzarle responsabilidad penal, asume el pasivo civil, quedando, por disposición de la ley, solidariamente obligado con el o los responsables penales. 


\section{CONCLUSIONES}

1. La víctima ha estado olvidada por el sistema penal. Diversas han sido las circunstancias que han cooperado a esta situación. En primer lugar, con la aparición del Estado moderno, la titularidad de la potestad punitiva aparece como una manifestación irrenunciable de la soberanía del Estado. Por otra parte, el contenido cada vez más abstracto que la doctrina asigna al bien jurídico lleva al legislador a desplazar su interés hacia el hecho delictivo entendido no tanto como perjuicio ocasionado a la víctima, como puesta en peligro o lesión de determinados bienes esenciales para el normal funcionamiento de la sociedad. Por último, las ideas ilustradas expresadas por los correccionalistas propician los derechos del inculpado. Ideas asentadas hoy en la generalidad de las constituciones en el principio de la resocialización del delincuente. ${ }^{30}$

2. Nuestro Código Procesal Penal Peruano, en su título IV, titulado "La víctima", contiene importantes innovaciones que favorecen la participación procesal a la víctima. Sin embargo, ello no garantiza que la víctima se encuentre amparada para el acompañamiento del Estado en la reparación del daño causado.

3. Hay que anotar, como ya se ha dicho, que la víctima debe ser también asistida en sus garantías mínimas de protección; no olvidemos que la víctima ya sufrió un perjuicio, en algunos casos irreparable. El estado peruano, a raíz de la dación del Nuevo Código Procesal Penal ha hecho esfuerzos por darle una protección mínima a la víctima, expidiéndose dos normas importantes, como son el Reglamento del Programa de Asistencia a Víctimas y Testigos, y el Reglamento del Programa integral de protección a testigos, peritos, agraviados o colaboradores que intervengan en el proceso penal, mediante el D.S. 003-2010 - JUS. Sin embargo, estas normas no han sido suficientes para proteger a la víctima, ya que también dictan protección a otros sujetos procesales.

4. Al derecho de defensa de la víctima corresponde: i) Una defensa material, cuando sea la propia víctima quien ejerza su defensa, ya sea declarando la forma en que ocurrieron los hechos o sustentando su pretensión de reparación civil; y ii) una defensa técnica, que implica su derecho a ser asesorada por un abogado, el que debería proveerle el Estado. A tal efecto, se ha implementado por el Ministerio Público, dentro de su Unidad de Asistencia a Víctimas y Testigos, un equipo de profesionales del Derecho que deberían asesorar a las víctimas en todo lo que necesite; sin embargo, es de reconocer que su efectividad actualmente es muy relativa. ${ }^{31}$

30 Estudio Benites, Forno, Ugaz y Ludowieg, Andrade Abogados. En: Revista de Análisis Especializado de Jurisprudencia RAE - Jurisprudencia. Editorial ECB, 2012.

31 Gaceta Penal y Procesal Penal. “Información actualizada para abogados y jueces”. Tomo 46, abril 2013, p. 269. 
5. Así mismo, debemos precisar que la norma no tiene como objeto reconocer y garantizar los derechos de la víctima en todos sus sentidos. La norma en comento tiene como objeto dar protección a la víctima y testigos que se encuentren en riesgo con ocasión de su participación en una investigación o proceso. Ello quiere decir que si no se encuentra en riesgo la participación de la víctima dentro del proceso, no será beneficiada con dicha norma.

6. La casuística peruana nos muestra dos tipos de problemas: a) Es frecuente que se establezca un monto de reparación civil que resulta desproporcionado en relación a la naturaleza y características del daño ocasionado por el delito, y b) el uso de fórmulas generales para fijar determinada reparación civil que carecen de motivación.

7. Por último para concluir el presente artículo, considero que se hace urgente y necesaria una Ley General de Víctimas que pueda comprender a la "víctima” sin distinción alguna, incorporándole, entre otros derechos:

1. Derechos de ayuda, asistencia y atención, para cuyo fiel cumplimiento podría comprenderse a los Gobiernos Locales y Gobiernos Regionales.

2. Derecho de acceso a la justicia, por el que se garantice la reparación civil de la víctima.

3. Derecho a la reparación integral, de modo que se expresen medidas claras de no repetición de la agresión a la víctima.

4. Derecho de la víctima a ser atendida inmediatamente una vez producida la agresión, de tal manera que se garantice por parte del Estado su atención hospitalaria, medicamentos, servicios de análisis médicos, entre otros, hasta que la víctima se encuentre totalmente recuperada. Se deberá extender un programa de nutrición cuando la atención sea para la víctima materno-infantil.

5. Derecho a protección, alojamiento y alimentación para aquellas víctimas que se encuentran en situación vulnerable o que se encuentren amenazadas por su agresor.

6. Derecho a la rehabilitación, en la que se comprenda atención médica, psicológica y psiquiátrica.

7. Medidas de compensación que comprendan la reparación del daño sufrido en la integración física del mismo.

Podríamos seguir enumerando derechos; sin embargo, considero que, de acuerdo a la Victimología, en nuestro país se requiere de la urgente promulgación de una Ley General de Victimas. 
La ley propuesta daría además mayor protagonismo a la víctima dentro del proceso penal y estaría cercana a la realidad expuesta en este trabajo, contribuyendo de este modo a la renovación del Derecho Penal, posibilitando una reparación integral como auténtica solución del conflicto.

Se deja finalmente una interrogante que nos lleva a reflexión: ‘alguien en el Perú paga la reparación civil?

Una Ley General de Víctimas posibilitará que la víctima sea realmente "resarcida", cumpliéndose la finalidad que señala el Código Penal: reparar el daño o efecto que el delito ha tenido sobre la víctima, ya que la propuesta comprende la asistencia, que trata de ser completa, atendiendo a la afectación concreta generada por el delito. 


\section{REFERENCIAS}

- Chinchay Castillo, Alcides. "La víctima y su reparación civil". En: Jurisprudencia Penal. № 108, setiembre 2007.

- Flavio Gomes, Luiz. "La Victimología y el modelo consensual de justicia criminal". En: Revista Peruana de Doctrina y Jurisprudencia Penal. Grijley, 2000.

- Gaceta Penal y Procesal Penal. "Consultas. ¿Cómo se configura el derecho de la defensa del agraviado o víctima del delito en el proceso penal?”. Tomo 46, abril 2013.

- Gaceta Penal y Procesal Penal. "Información actualizada para abogados y jueces". Tomo 46, abril 2013.

- García-Pablos de Molina, Antonio. Criminología. Primera edición. Instituto Peruano de Criminología y Ciencias Penales. Centro de Educación Continua, 2008.

- Jorge Mesas, Luis Francisco. "La eficacia del sistema penal". En: Cuadernos del Poder Judicial. Dedicado a Criminología. Consejo General del Poder Judicial. Madrid, 1994.

- Neyra Flores, José Antonio. Manual del Nuevo Proceso Penal y de litigación oral. IDEMSA, 2010.

- Oré Guardia, Arsenio. Manual de Derecho Procesal Penal. Editorial Reforma S.A., 2011.

- Peña Cabrera Freyre, A. Exégesis. Nuevo Código Procesal Penal. 2da. edición. Bilbao: Editorial Praxis, 1999.

- Reyna Alfaro, Luis. El proceso penal aplicado. Grijley, 2011.

- Rodríguez Manzanera. "Victimología y derechos humanos". En: Revista Mexicana de Justicia. No 4, vol V, 1987.

- Rosillo Sánchez, Omar Levi. "La víctima y el testigo en el Código Procesal Penal de 2004". En. Revista de Actualidad Jurídica. No197, 2010.

- Roxin, Claus: "La reparación en el sistema jurídico-penal de sanciones", traducción de Manzanares, Jornada sobre la Reforma del Derecho Penal en Alemania, C.G.P., Madrid 1991.

- Sánchez Velarde, P. El nuevo proceso penal. Lima: IDEMSA, 2009.

- Silva Sánchez, Jesús María. "La Víctimología desde la política criminal y el Derecho Penal. Introducción a la "Victimodogmática". En: Revista Peruana de Ciencias Penales. Año II, No 4, julio-diciembre de 1994.

- Solís Espinoza, Alejandro. "Criminología y Victimología”. En: Debate Penal. Revista Cuatrimestral, año I, No 3, setiembre-diciembre de 1987. 
- Sosa Chacín, Jorge. "La Victimología, pretendida ciencia autónoma”. En: Revista de la Facultad de Derecho. Caracas, 1968, № 40.

- Vasallo Sambuceti, E. La acción civil en el proceso penal. Lima: Editorial San Marcos, 2000.

- Villegas Paiva, Elky. El agraviado y la reparación civil en el nuevo Código Procesal Penal. Primera edición. Editorial Gaceta Jurídica S.A., 2013. 